\title{
REVIEW
}

\section{Nanoparticle biosynthesis using unicellular and subcellular supports}

\author{
Cheng-Hung Luo ${ }^{1}$, Vijayakumar Shanmugam ${ }^{2}$ and Chen-Sheng Yeh $^{1}$
}

Modern life is becoming increasingly sophisticated because of products engineered using designs inspired by nature. Fifty years ago, the burdock plant motivated Swiss scientists to invent Velcro, which was a simple but widely applied design that is still considered the greatest biomimetic invention yet. In nanotechnology, interest in biosynthesis of nanoparticles is increasing, particularly in the use of unicellular and subcellular supports. However, the polydispersity of the resultant structure, limited opportunity for product control and commercial applications of biosynthesized nanoparticles remain as challenges. Using different approaches, studies have attempted to understand nanoparticle biosynthesis and control of particle size and uniformity. In the biotechnological approach, gene sequences that were identified in one organism via gene silencing and were critical for nanoparticle synthesis were introduced and expressed in a different organism or overexpressed by promoters in the same organism to enhance productivity. In contrast, physical and chemical approaches were used for the control of nanoparticle synthesis. To provide a comprehensive understanding of nanoparticle biosynthesis using unicellular and subcellular supports, this review discusses recent studies and experimental evidence in the following categories: synthesis of metal, quantum dot, magnetic and bacterial protein nanoparticles.

NPG Asia Materials (2015) 7, e209; doi:10.1038/am.2015.90; published online 14 August 2015

\section{INTRODUCTION}

Nature continues to provide inspiration for many nanotechnological applications. Even after much study, it remains challenging to design a system as perfect as that found in nature. In nature, replication occurs precisely, with notably few defects. Hence, the optimal approach for mimicking natural systems is to begin with simple systems. Unicellular systems that are a few microns in size (such as bacteria) can sense their habitat, for example, Thiobacillus ferrooxidans senses iron-rich habitats and uses iron to generate energy for its growth and development. ${ }^{1}$ To apply microbial behavior in the synthesis of nanoparticles, scientists must focus additional attention on such unicellular systems to understand the mechanisms underlying biosynthesis and apply the merits of these mechanisms.

In the past few decades, studies have examined the biochemical and genetic aspects of unicellular organisms; however, applications of the derived information to nanoparticles biosynthesis have yet to be completely explored. With respect to unicellular organisms, certain metal-resistant bacteria have been used for nanoparticle synthesis. ${ }^{2}$ These bacteria have a basic defense or adaptive mechanism in which the anionic components of biological systems (for example, cell membranes, proteins and DNA) encounter cations, resulting in Coulomb interactions and thus the checking of the regular functions of these systems. Consequently, a reduction, hydrolysis or chelation process leads to the formation of metal, metal oxide or metal sulfide nanoparticles. ${ }^{3}$ However, microorganisms adopted for nanoparticle synthesis have not gained considerable attention because of the inhomogeneity of the resulting particle sizes and shapes as well as concerns associated with scale-up of the nanoparticle synthesis process for practical use. ${ }^{4}$ Many reactions that run in parallel might cross-react in the micro-sized reaction vessels of the organisms, which leads to inhomogeneity in nanoparticle synthesis.

To date, studies that identify the genes responsible for nanoparticle biosynthesis have been conducted using either gene silencing, that is, the expected genes responsible for synthesis are silenced to facilitate identifying their role in nanoparticle synthesis, or gene introduction, that is, the candidate gene clusters are introduced into other organisms to verify the ability of the gene clusters to initiate nanoparticle biosynthesis in the organisms of interest. The aforementioned strategies are crucial for understanding the natural mechanisms underlying nanoparticle synthesis. In addition, the studied mechanisms could facilitate a solution to the problem of inhomogeneity. For example, proteins synthesized using the responsible genes can be upregulated or isolated and their functions can be executed separately, or the supply of precursor reactants to cell extracts encapsulated in lipid or polymer artificial compartments can be controlled. Consequently, the upregulation of specific proteins causes other

${ }^{1}$ Department of Chemistry and Advanced Optoelectronic Technology Center, National Cheng Kung University, Tainan, Taiwan and ${ }^{2}$ Institute of Nano Science and Technology, Habitat Centre, Phase-X, Sector-64, Punjab, India

Correspondence: Dr V Shanmugam, Institute of Nano Science and Technology, Habitat Centre, Phase-X, Sector-64, Mohali, Punjab 160062, India.

E-mail: vijayakumarshanmugham@gmail.com

or Professor C-S Yeh, Department of Chemistry and Advanced Optoelectronic Technology Center, National Cheng Kung University, Tainan 701, Taiwan.

E-mail: csyeh@mail.ncku.edu.tw

Received 30 March 2015; revised 12 June 2015; accepted 21 June 2015 
functional proteins to remain in a less active state, and control of the reactant supply could have a role in controlling the nucleation and growth of metal nanoparticles. ${ }^{3,5-7}$ These strategies facilitate the formation of nanoparticles of homogeneous sizes and shapes. A study using microfluidics showed promising results for potential scale-up. ${ }^{4}$ In this review, the challenges associated with the use of microfluidic approaches are discussed together with other novel improvements in nanoparticle biosynthesis. We particularly focus on the synthesis of metal, metal oxide, quantum dot (QD), magnetic and protein nanoparticles.

\section{METAL NANOPARTICLE SYNTHESIS}

Metal nanoparticles have attracted considerable interest in the field of nanoscience because of their optical, magnetic, electric and thermal properties. However, despite decades of refinement in metal nanoparticle synthesis, chemical synthesis of nanoparticles with high stability remains challenging, particularly under adverse conditions. In contrast, metal nanoparticles synthesized using biological methods have shown excellent stability, for example, Ag nanoparticles synthesized using bovine serum albumin as a reducing agent showed excellent stability under extreme $\mathrm{pH}$ and salt conditions. ${ }^{8}$ Furthermore, biosynthesis methods are considered green approaches and have attracted substantial interest. In this section on the recent developments in metal nanoparticle synthesis, we discuss $\mathrm{Cu}$ nanoparticle synthesis, shape-controlled biosynthesis of metal nanoparticles using cell extracts and plasmid DNA, sitespecific metal nanoparticle placement using bacterial membranes as masks and Au nanoparticle synthesis.

Ramanathan et al. ${ }^{9}$ used the Morganella morganii strain RP42 to overcome the inhomogeneity problem in $\mathrm{Cu}$ nanoparticle synthesis in the aqueous phase because $\mathrm{Cu}$ nanoparticle synthesis often resulted in a copper oxide surface in aqueous phase synthesis. M. moranii is resistant to silver. Incubating these bacteria with a high $\mathrm{Cu}$ ion concentration $(3 \mathrm{~mm})$ resulted in $\mathrm{Cu}$ nanoparticles approximately $19-\mathrm{nm}$ in size. These particles showed a characteristic UV-Vis absorbance at $550-600 \mathrm{~nm}$, and the electron diffraction patterns matched the spacing of $0.21,0.181,0.128$ and $0.112 \mathrm{~nm}$ corresponding to zero-valent $\mathrm{Cu}$. Surface-sensitive X-ray photoelectron spectroscopy measurements were performed to assess the presence of pure $\mathrm{Cu}$ and showed strong binding energy peaks of $\mathrm{P}_{3 / 2}$ and $\mathrm{P}_{1 / 2}$ at 933 and
$953 \mathrm{eV}$, respectively, of zero-valent $\mathrm{Cu}$ and the absence of the shakeup satellite peak typically associated with $\mathrm{CuO}$. To verify the formation mechanisms, linear sweep voltammetry was performed on bacteria collected as a function of the incubation time with $\mathrm{Cu}$ ion solutions. Bacterial pellets were thoroughly washed to remove any contamination (for example, sugar and other salts from incubation media) and were placed on the working electrode. When a voltage of $-0.99 \mathrm{~V}$ was applied against an $\mathrm{Ag} / \mathrm{AgCl}$ reference, a single peak appeared. Subsequently, a second peak was observed that intensified with incubation time. The initial less negative potential peak was attributed to the reduction of $\mathrm{Cu}$ ions, and the later more positive potential peak was attributed to the oxidation of the $\mathrm{Cu}$ nanoparticles synthesized by the bacteria. In another study, $\mathrm{Cu}$ nanoparticle synthesis was performed using both live and dead biomasses of Rhodotorula mucilaginosa. Dead biomass prepared by autoclaving formed $\mathrm{Cu}$ nanoparticles more efficiently than live biomass. ${ }^{10}$ Dead biomass is advantageous for $\mathrm{Cu}$ formation because of the absence of toxicity and no requirement for growth media. Changes in $\mathrm{pH}$, temperature and agitation speed are essential for the adsorption of cations. Compared with the live biomass preparation of yeast, the dead biomass preparation exhibited rapid $\mathrm{Cu}$ ion removal, leading to $\mathrm{Cu}$ nanoparticle formation within $1 \mathrm{~h}$. Cytoplasmic proteins were suggested to act as reducing agents. The presence of $\mathrm{CuO}$ and $\mathrm{Cu}_{2} \mathrm{O}$ was ruled out because of the absence of the $933.7-\mathrm{eV}$ and satellite peaks resulting from $\mathrm{CuO}$ and $\mathrm{Cu}_{2} \mathrm{O}$, respectively.

Using organelles from unicellular organisms, a study demonstrated size- and shape-controlled nanoparticle synthesis. ${ }^{11}$ In that study, plasmids with circular DNA composed of 3980 nucleotides were isolated from the Bacillus host. The plasmids were allowed to form stable complexes with Ag ions through electrostatic attraction. After $1 \mathrm{~h}$ of UV irradiation at $254 \mathrm{~nm}$, the plasmids formed complexes with $\mathrm{Ag}$ ions and showed the characteristic absorbance of Ag nanoparticles at $420 \mathrm{~nm}$ (Figure 1). A control experiment was conducted with UV photoirradiation of $\mathrm{AgNO}_{3}$ without the plasmids, and these solutions did not show the characteristic 420-nm absorbance, thus indicating the role of plasmids as reducing agents. This plasmid-assisted nanoparticle synthesis resulted in nanoparticles of homogenous sizes and shapes, as confirmed by transmission electron microscopy (TEM) measurements. The synthesis kinetics showed formation of ring-shaped $\mathrm{Ag}$ nanoparticles caused by the reduction of $\mathrm{Ag}$ ions a

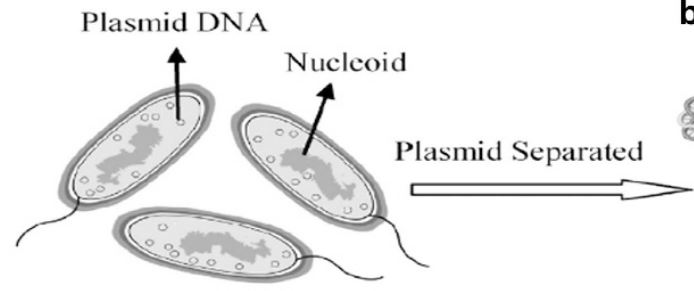

b
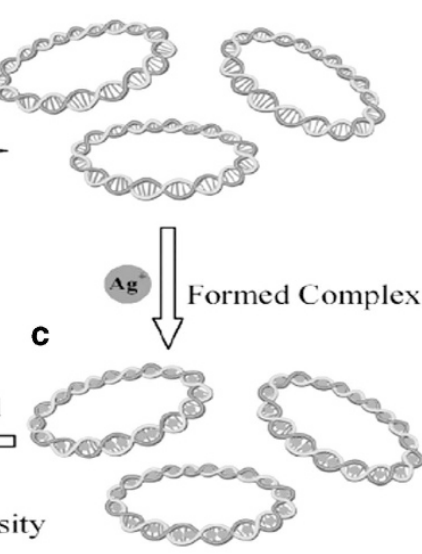

Figure 1 Synthesis of circular and ring-shaped Ag nanoparticles using bacterial plasmids as templates. (a, b) Plasmid isolation from the Bacillus host $\rightarrow$ (c) Plasmid-Ag ion complex formation $\rightarrow$ (d) UV-photoirradiation-assisted plasmid oxidation accompanied by Ag ion reduction. Reproduced with permission. ${ }^{11}$ Copyright 2012, WILEY-VCH. 
adsorbed on the plasmids after photo-oxidation of the plasmids. The photo-oxidation of the plasmids by UV irradiation was demonstrated by the decrease in plasmid absorbance at $260 \mathrm{~nm}$. This decrease in the 260-nm absorbance was accompanied by a proportional increase in the $420-\mathrm{nm}$ absorbance, indicating that the photo-oxidation facilitated the reduction of Ag ions. Subsequently, the reduced $\mathrm{Ag}$ metal rings further catalyzed the reduction of $\mathrm{Ag}$ ions and yielded circular Ag nanoparticles. In the experiment, the plasmids served as reducing and templating agents. Because the plasmids can be harvested in multiple copies without error from the bacterial factories, this approach is promising for synthesis of nanoparticles with homogenous sizes and shapes.

A study involving site-specific metal nanoparticle placement using bacterial membranes was also reported ${ }^{12}$ using membranes of Mycobacterium smegmatis (which have less permeability than those of Escherichia coli). In M. smegmatis cell membranes, the 10-nm-long hydrophilic channels, that is, porin MspA, have a major role in cellular transport of the hydrophilic pathway. MspA was found to be stable even after treatment with $2 \%$ sodium dodecyl sulfate in a $\mathrm{pH}$ range of $0-14$. The isolated MspA was docked onto the self-assembled organic thiosulfates, namely, $\mathrm{C}_{19} \mathrm{H}_{27} \mathrm{NaO}_{6} \mathrm{~S}_{2}, \mathrm{C}_{39} \mathrm{H}_{67} \mathrm{NaO}_{8} \mathrm{~S}_{2}, \mathrm{C}_{39} \mathrm{H}_{69} \mathrm{NaO}_{8} \mathrm{~S}_{2}$, $\mathrm{C}_{37} \mathrm{H}_{65} \mathrm{NaO}_{8} \mathrm{~S}_{2}, \mathrm{C}_{59} \mathrm{H}_{107} \mathrm{NaO}_{10} \mathrm{~S}_{2}$ and $\mathrm{C}_{79} \mathrm{H}_{147} \mathrm{NaO}_{12} \mathrm{~S}_{2}$, with lengths of $2.11,4.77,4.54,4.53,7.50$ and $10.24 \mathrm{~nm}$, respectively. These organic thiosulfates were electrodeposited on $\mathrm{Au}$ plates in the presence of $\mathrm{CH}_{3} \mathrm{CN}$ and $\mathrm{LiClO}_{4}$. Subsequently, MspA proteins in the buffer were allowed to arrange on the self-assembled layer, where the approximately 5 -nm organic chains exhibited optimal reorganization (Figure 2). The self-assembled layers embedded with MspA proteins with pores were used as templates for the electrodeposition of $\mathrm{Cu}$ nanoparticles via the overpotential deposition process following two 5 -s short pulses of $-0.035 \mathrm{~V}$ and a 15 -s long pulse of $0.02 \mathrm{~V}$. The resulting $\mathrm{Cu}$ nanoparticles formed in the assembled layers have potential applications as transistors. Next, an E. coli strain (116AR) with the CusCFBA $\mathrm{Cu} / \mathrm{Ag}$ efflux system, that is, a gene cluster that expresses the membrane proteins involved in $\mathrm{Cu}$ and $\mathrm{Ag}$ efflux, showed strong resistance to $\mathrm{Ag}$ ions and allowed the accumulation of Ag nanoparticles in the periplasmic space after prolonged exposure to $\mathrm{AgNO}_{3} .{ }^{13}$ The facultative anaerobic E. coli preferably synthesized Ag nanoparticles under anaerobic conditions. The c-type cytochromes, which form the membrane-anchored tetra-heme c-type cytochrome subunits for the periplasmic nitrate reductase, had a major role in the biosynthesis of $\mathrm{Ag}$ nanoparticles. Overnight culture with $\mathrm{AgNO}_{3}$ under anaerobic conditions turned the medium to an intense amber color and exhibited an absorption peak at $440 \mathrm{~nm}$ corresponding to the peak
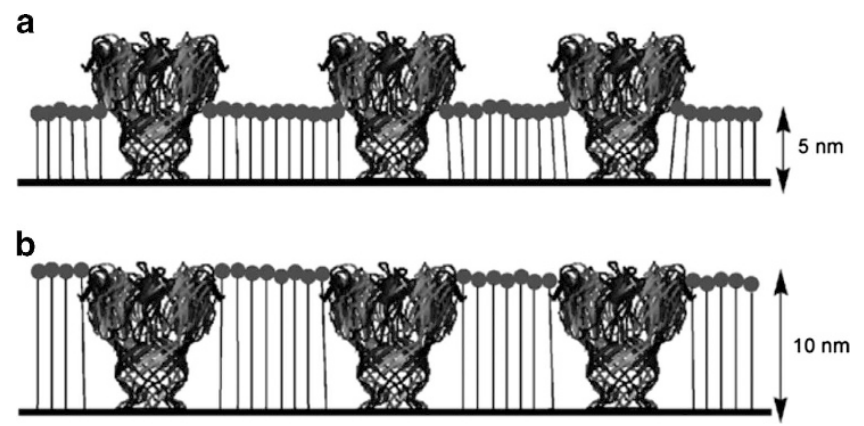

Figure 2 MspA proteins (flower vase-like structures) arranged on different lengths ( 5 and $10 \mathrm{~nm}$ in panels $\mathbf{a}$ and $\mathbf{b}$, respectively) of organic thiosulfates (lines with head-like structures) and electrochemically assembled on thin $\mathrm{Au}$ films. Reproduced with permission. ${ }^{12}$ Copyright 2007, WILEY-VCH. of Ag nanoparticles. The TEM images revealed spherical nanoparticles deposited in the periplasmic spaces of the bacterial cell walls, and energy-dispersive X-ray spectroscopy (EDX) and selected area electron diffraction (SAED) patterns confirmed the presence of highly crystalline Ag nanoparticles.

Correa-Llanten et al. ${ }^{14}$ summarized the biosynthesis of Au nanoparticles discovered in various bacteria, such as E. coli, Bacillus subtilis, Pseudomonas aeruginosa, Lactobacillus species and Rhodopseudomonas capsulata. Although soluble $\mathrm{Au}$ ions are toxic, these bacteria are resistant to $\mathrm{Au}$ ions and can reduce $\mathrm{Au}$ ions to metallic $\mathrm{Au}$ in $\mathrm{Au}-$ containing media. Cupriavidus metallidurans and Delftia acidovorans were found to synthesize Au nanoparticles and yielded Au nuggets in bacterial biofilms. ${ }^{15}$ C. metallidurans accumulated Au nanoparticles within the cytoplasm to protect cells from the Au ions. D. acidovorans generated a diffusible metabolite that reduced the soluble $\mathrm{Au}$ ions to form $\mathrm{Au}$ nanoparticles. In silico predictions showed that the del cluster, that is, a gene cluster producing secondary metabolites for the reduction of $\mathrm{Au}$ ions, was associated with metabolite synthesis and the inactivation of the gene nonribosomal peptide synthetase (delG), which resulted in no reduction of $\mathrm{Au}$ ions. The secreted metabolites were subjected to liquid chromatography-mass spectrometry measurements, which showed that the final structure for the Au-interacting nonribosomal peptides was delftibactin, which interacted with $\mathrm{Au}$ in $\mathrm{D}$. acidovorans. Moreover, exposure of delftibactin to soluble Au ions in the presence of Fe (III) led to the formation of octahedral Au nanoparticles.

Geobacillus species also can biosynthesize $\mathrm{Au}$ nanoparticles. ${ }^{14,16}$ Intracellular reduction of $\mathrm{Au}$ ions yielded $\mathrm{Au}$ nanoparticles in Geobacillus sp. strain ID17. When the cells were suspended in a $\mathrm{KH}_{2} \mathrm{PO}_{4}$ buffer with $\mathrm{HAuCl}_{4}$ ( $\mathrm{pH} 7.0$ ), their color changed from pale yellow to intense purple after incubation for $16 \mathrm{~h}$ at $65^{\circ} \mathrm{C}$. TEM images showed the intracellular localization of Au nanoparticles with different size distribution. The nanoparticles were predominantly hexagonal, with diameters in the range of 5-50 nm. An EDX spectrum revealed that $94.6 \%$ of the particles corresponded to Au nanoparticles. The Fourier transform infrared spectroscopy spectrum revealed the primary amine and amide peaks at 3299 and $1658 \mathrm{~cm}^{-1}$, respectively. The stretching peak observed at $2422 \mathrm{~cm}^{-1}$ indicated the presence of aliphatic $\mathrm{C}-\mathrm{H}$ bonds. In addition, the peaks of $\mathrm{C}-\mathrm{N}$ bonds appeared in the range of $1250-1000 \mathrm{~cm}^{-1}$. The Fourier transform infrared spectroscopy results suggested that protein molecules with aromatic amine groups possibly capped the surfaces of Au nanoparticles. The $\mathrm{NADH}$-dependent reductase analysis of the crude extracts of ID17 cells showed the role of the extracts in catalyzing $\mathrm{Au}^{3+}$ reduction. Zymogram analysis, which is a reduced protein gel electrophoresis performed for in-gel reaction analysis, further revealed the proteins involved in $\mathrm{Au}^{3+}$ reduction. ${ }^{14}$ Zymogram analysis involves the use of polyacrylamide gel electrophoresis to separate various proteins extracted from cells into different bands according to size. The authors used this technique to identify the proteins from bacterial cells that interact with Au ions. G. stearothermophilus, a Geobacillus sp. strain ID17 relative, was also demonstrated to reduce $\mathrm{Au}$ and $\mathrm{Ag}$ ions. The UV-Vis spectra were used to observe the surface plasmon characteristics of $\mathrm{Au}$ and $\mathrm{Ag}$ reduction subjected to the incubation of cations with cell-free extracts. The crystal structures of Au and Ag nanoparticles were confirmed according to the XRD patterns. The Fourier transform infrared spectroscopy patterns of the $\mathrm{Au}$ and $\mathrm{Ag}$ nanoparticles showed capping ligands possibly associated with the proteins that possessed cysteine residues with peaks at $1650 \mathrm{~cm}^{-1}$, $1540 \mathrm{~cm}^{-1}$ and $1450 \mathrm{~cm}^{-1}$. The cross-interactions of the proteins and enzymes with the reactants in the bacteria resulted in polydispersity of 
the nanoparticles in the biosynthesis. Thus, isolation of the exact proteins responsible for reduction and capping is an area of interest. Accordingly, sulfite reductase and capping proteins isolated from a Thermomonospora sp. were used for $\mathrm{Au}$ nanoparticle synthesis ${ }^{17}$ in which monodisperse nanoparticles were generated because cross-reactions were completely avoided.

For studies of kinetic control of the quasi-biological formation of gold clusters, biomimetic methods were applied to adjust the reducing activity to slow the reduction process relative to the activity of a chemical reducing agent such as $\mathrm{NaBH}_{4} \cdot{ }^{18}$ In the initial stage, $\mathrm{Au}(\mathrm{I})$ stably complexed with $\mathrm{Cl}^{-}$and glutathione (GSH). Because of the favorable redox potential, $\mathrm{Au}(\mathrm{I})$ was reduced to yield $\mathrm{GSH}$-capped gold nanoparticles. The reducing agents could be $\beta$-nicotinamide adenine dinucleotide 2'-phosphate (NADPH) coupled with glutathione reductase (GR) in biomimetic reduction process. The products of the gold nanoclusters (Au NCs) were characterized using laser-desorption-ionization mass spectrometry. The estimated mass of the $\mathrm{Au} \mathrm{NC}$ was $12.4 \mathrm{kDa}$ and was calculated to show that the core consisted of approximately $60 \mathrm{Au}$ atoms. Such GSH-protected quantum-sized Au NCs revealed the absence of a surface plasmonic band in the UV-Vis spectrum. However, the circular-dichroism (CD) spectrum showed the GSH-Au NCs spectra above $250 \mathrm{~nm}$, which was absent in pure GSH or Au nanoparticles alone, indicating attribution from Au NC cores. The biomimetic synthesis of Au NCs provided realization of kinetically controlled formation of $\mathrm{Au}$ clusters under mild reducing conditions.

\section{METAL OXIDE NANOPARTICLES}

Ma et al. ${ }^{19}$ used Saccharomyces cerevisiae for the intracellular biosynthesis of $\mathrm{CaCO}_{3}$ nanoparticles. Composite yeasts containing intracellular $\mathrm{CaCO}_{3}$ nanoparticles were loaded with doxorubicin hydrochloride (DOX) and applied in a $\mathrm{pH}$-sensitive drug delivery system. The yeast cells were activated with maltose for $\mathrm{CO}_{2}$ release, followed by the addition of saturated $\mathrm{Ca}(\mathrm{OH})_{2}$. The $\mathrm{Ca}^{2+}$ ions permeated into the cells and combined with the $\mathrm{CO}_{2}$ release to form $\mathrm{CaCO}_{3}$ nanoparticles. Both XRD and EDX analysis revealed the presence of diffused $\mathrm{Ca}^{2+}$ inside the cells, which is required for intracellular nanoparticle formation. In addition, the intracellular placement of nano- $\mathrm{CaCO}_{3}$ was confirmed through fluorescence confocal microscopy using tetracycline hydrochloride as a $\mathrm{CaCO}_{3}$-specific fluorescence marker. For brevity, S. cerevisiae with nano- $\mathrm{CaCO}_{3}$ is denoted as nanoCaCO $3 @$ S.c. Biocompatibility studies of nanoCaCO${ }_{3} @ S . c$ were performed following a tryphan blue exclusion assay and flow cytometry and demonstrated 93\% cell viability. In the subsequent step, nanoCaCO $\mathrm{C}_{3} @ S . c$ was incubated with DOX for $17 \mathrm{~h}$ to load DOX. The successful encapsulation of DOX into nanoCaCO $3 @ S . c$ was attributed to the interaction of $\mathrm{Ca}^{2+}$ ions with the -CO and -OH groups of DOX. The DOX-nanoCaCO @S.c selectively delivered and released the drug at a low $\mathrm{pH}$ in the PC-12 cancer cell line and showed control over cancer cell growth.

Silver oxide nanoparticles represent another interesting class of metal oxides that occur in various forms, for example, $\operatorname{Ag}_{2} \mathrm{O}, \mathrm{AgO}$, $\mathrm{Ag}_{3} \mathrm{O}_{4}$ and $\mathrm{Ag}_{2} \mathrm{O}_{3}$. For example, $\mathrm{Ag}_{2} \mathrm{O}$ has applications in oxidation catalysts, sensors and fuel cells. Lactobacillus mindensis-mediated biosynthesis of $\mathrm{Ag}_{2} \mathrm{O}$ was achieved by incubating the bacteria in an $\mathrm{AgNO}_{3}$-containing medium in the dark for 5 days to avoid photochemical reduction. ${ }^{20}$ However, TEM images of the resulting $\mathrm{Ag}_{2} \mathrm{O}$ nanoparticles showed inhomogeneity in size and shape with slight particle aggregation. The SAED patterns showed the plane (111) of $\mathrm{Ag}_{2} \mathrm{O}$ nanoparticles, and the XRD patterns confirmed $\mathrm{Ag}_{2} \mathrm{O}$ peaks.

\section{QUANTUM DOT NANOPARTICLE SYNTHESIS}

QDs are semiconductors for which the optical properties depend on their band gaps, and these constructs have great potential in photoluminescent applications. Dameron et al. ${ }^{21}$ published the pioneering report on biosynthesis of CdS QDs with sizes of $2 \mathrm{~nm}$ in diameter in the yeasts Candida glabrata and Schizosaccharomyces pombe. The biosynthesized CdS QDs displayed better monodispersity than those from chemical preparation. The CdSe nanoparticles are one of the examples that exhibit fluorescent tags. Xie et al. ${ }^{22}$ reported the intracellular synthesis of CdSe nanoparticles in S. cerevisiae. The authors recently elucidated the mechanisms of CdSe nanoparticle synthesis using genetic engineering techniques that facilitated enhanced biosynthesis of the nanoparticles. ${ }^{5}$ The metabolic pathway of glutathiones with both peptide and thiol features was silenced in the yeasts after interaction with inorganic ions. The genes GSH1, GSH2 and GLR1 contribute to glutathione biosynthesis (Figure 3). Silencing of GSH1, GSH2 and GLR1 in wild-type yeasts, which are denoted as a

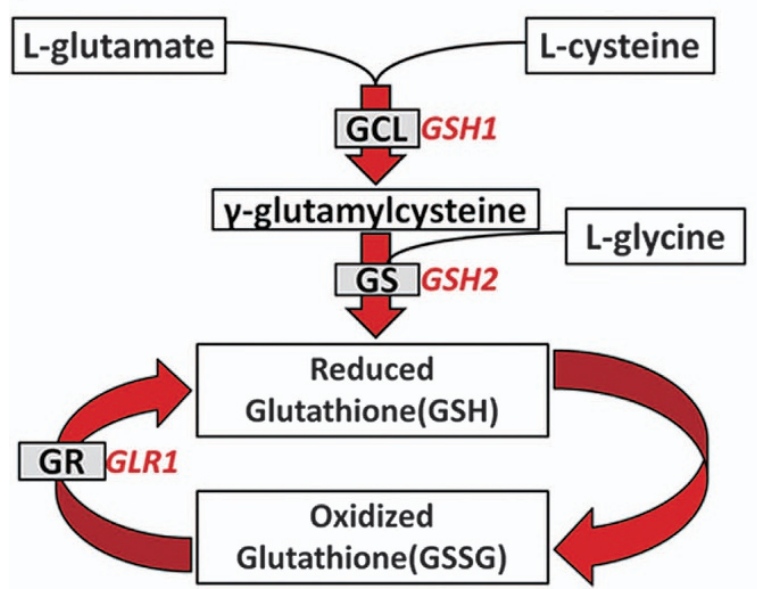

b
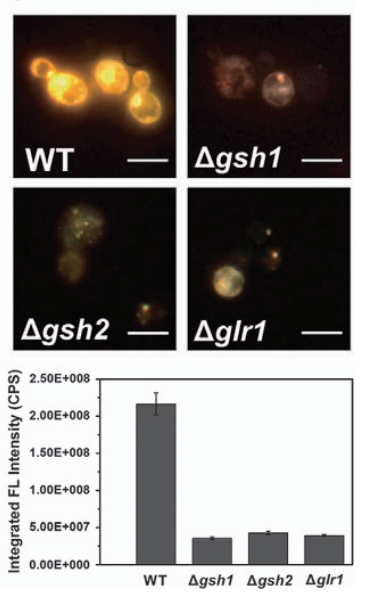

Figure 3 (a) Glutathione biosynthesis in yeasts with GSH1, GSH2 and GLR1 genes. (b) Gene silencing of GSH1, GSH2 and GLR1 in wild-type (WT) yeasts, denoted as $\Delta \mathrm{gsh} 1, \Delta \mathrm{gsh} 2$ and $\Delta \mathrm{g} \mid \mathrm{r} 1$, respectively, showed significant reduction in nanoparticle fluorescence. Reproduced with permission. ${ }^{5}$ Copyright 2013 , American Chemical Society. 
$\Delta$ gsh1, $\Delta$ gsh2 and $\Delta$ glr1, respectively, showed a significant reduction in fluorescence. The reduction in fluorescence was proportional to that in CdSe nanoparticle synthesis. The authors examined the synthesis efficiency of CdSe nanoparticles using the same population of cells in the exponential and stationary phases and confirmed that the stationary phase was favorable for the efficient biosynthesis of the CdSe nanoparticles. The authors performed CdSe synthesis as follows. First, $\mathrm{Na}_{2} \mathrm{SeO}_{3}$ was reduced to selenocysteine (Cys-Se) $)_{2}$, a complex of selenium-containing cysteine. Second, $\mathrm{CdCl}_{2}$ was added to react with the selenocysteines to generate CdSe nanoparticles. Selenocysteine synthesis was not significantly affected by gene silencing, but CdSe nanoparticle synthesis was hindered, thus showing the importance of glutathiones for this step. The function of GSH1, GSH2 and GLR1 genes with respect to CdSe nanoparticle synthesis was verified according to gene promotion in contrast to gene expression in the aforementioned silencing experiments. Accordingly, a galactose promoter was introduced to the GSH1, GSH2 and GLR1 genes. The presence of the galactose promoters enhanced glutathione biosynthesis, which proportionally increased nanoparticle synthesis. The galactose-promoter-induced GSH1 activation yielded a fivefold increase in the nanoparticle fluorescence.

An additional study revealed the biosynthesis mechanisms of CdSe QDs using S. cerevisiae. ${ }^{23}$ The authors used atomic force microscopy and real-time PCR (RT-PCR) analysis to monitor gene expression and observe the nanomechanical strength of viable yeast cells, which was crucial for the formation of CdSe QD nanoparticles. This strength depended primarily on the strength of the cell walls. The atomic force microscopy analysis indicated that the nanomechanical strength of the yeast cells for QD biosynthesis was markedly greater than that of the other cells. This finding suggests that cell wall thickness affects nanomechanical strength. Because the enzyme 1,3- $\beta$-glucan synthase (GS) is involved in cell wall synthesis in yeasts, the authors used RT-PCR to monitor the enzyme expression in the biosynthesis of QD. The expression of the GS gene in yeast cells synthesizing QDs was 8.1\% higher than that in yeast cells that did not synthesize QDs. Moreover, GSC2 and RHO1, which encode the GS subunits, were dramatically upregulated in the biosynthesis of yeast cells, as shown by RT-PCR analysis.

In another study, genetically engineered recombinant E. coli was used to demonstrate the synthesis of QDs as well as alkaline earth, magnetic, noble metal and rare earth nanoparticles. ${ }^{7}$ The cysteines in phytochelatin synthase $(P C)$ and metallothionein $(M T)$ were responsible for metal ion interaction. Using plasmids, $P C$ and $M T$ genes were transformed individually or in combination into the E. coli bacteria. Combination was achieved using two methods. First, the two genes were placed in different plasmids, and second, both genes were placed in a single plasmid construct. However, the use of either different plasmids or the single plasmid construct did not show significant differences with respect to the size, crystallinity and lattice parameter of QDs. For single-gene transformation, CdSe nanoparticles obtained from the bacteria transformed with $P C$ alone were similar to those obtained from the bacteria with co-expression of $P C$ and $M T$. Similarly, SeZn QDs obtained from the bacteria transformed with MT alone resembled those obtained from the bacteria transformed with the construct of both genes. Co-expression of the genes is suitable for synthesizing various nanoparticles such as those of $\mathrm{Au}, \mathrm{Ag}, \mathrm{Fe}, \mathrm{CdSe}$, CdTe, SrGd, FeAg, FeCo, FeMn, CdSeZn, FeCoNi, FeCoMn and AuCdSeZn. The CdSe nanoparticles obtained from the bacteria transformed with the construct exhibited fourfold higher fluorescence than those obtained from the bacteria transformed with either gene. Furthermore, gene regulation was characterized from CdTe QD synthesis in $E$ coli. ${ }^{24}$ The results showed that both the thiol content and redox state can promote CdTe QD synthesis. The bacterial cytoplasms exhibited a highly reducing environment and antioxidant defense by synthesizing reducing peptides such as glutathione.

Taking the advantage of the biological reduction environment, near-infrared (NIR) $\mathrm{Ag}_{2} \mathrm{Se}$ QDs with tunable fluorescence were quasi-biosynthesized using GSH, NADPH and glutathione reductase (GR). ${ }^{25}$ The biomimetic process for the reduction of $\mathrm{SeO}^{2-}$ led to GSSeH formation, and this precursor subsequently reacted with silver metal ions to form the $\mathrm{Ag}_{2} \mathrm{Se}$ QDs. In addition, the authors used the amino acid alanine (Ala) to form the $\mathrm{Ag}^{+}$-Ala complex, which is an important stabilizer for preparation of monodispersed $\mathrm{Ag}_{2} \mathrm{Se}$ QDs in aqueous phase. For tuning of the NIR photoluminescence, the ultra-small $\mathrm{Ag}_{2} \mathrm{Se}$ (less than $3 \mathrm{~nm}$ ) can be tuned to varying sizes via adjustment of the Ag:Se molar ratio, thus producing the size-dependent optical properties of $\mathrm{Ag}_{2} \mathrm{Se}$ QDs. As the size increased from 1.5 to $2.4 \mathrm{~nm}$, the photoluminescent emission peaks shifted from 700 to $820 \mathrm{~nm}$. Cell viability assays showed relatively less cytotoxicity among NIR nanomaterials when $\mathrm{Ag}_{2} \mathrm{Se}$ QDs were exposed to MDEK (normal kidney cells of cocker spaniel) and A549 cell (human lung carcinoma cells). Because of the biocompatible and water-dispersible properties, $\mathrm{Ag}_{2} \mathrm{Se}$ QDs demonstrated in vivo NIR fluorescence penetration. A similar concept for the biosynthesis of CdSe QDs in living Staphylococcus aureus was investigated by Xiong et al. ${ }^{26}$ The facile approach using intracellular GSH and reductase was able to reduce $\mathrm{Na}_{2} \mathrm{SeO}_{3}$ to organoselenium, followed by addition of $\mathrm{Cd}^{2+}$ to form the $\mathrm{Cd}$ precursor. These biochemical reactions intracellularly reacted precisely with endogenous mercapto biomolecules to form the $\mathrm{CdS}_{0.5} \mathrm{Se}_{0.5}$. With the expression of protein $\mathrm{A}$ on the surface of S. aureus cells, these bacteria were transformed into cellular beacons for pathogen detection using conjugation with various monoclonal antibodies.

The bio-associated synthesis of PbSe semiconductive nanoparticles with good monodispersity can precisely control the size of the product in water at temperature of $90{ }^{\circ} \mathrm{C} .{ }^{27}$ Cui et al. ${ }^{27}$ designed a quasi-biosystem with the involvement of GSH, HADPH and GR. The biochemical reaction reduced $\mathrm{SeO}_{3}{ }^{2-}$ to form the Se precursor GSSeH for subsequent reactions. Detoxification of $\mathrm{Pb}^{2+}$ cations was achieved by stabilizing the $\mathrm{Pb}$ precursor with $\mathrm{GSH}$ to form $[\mathrm{Pb}-\mathrm{GSH}]^{2+}$ complexes. Followed by reaction with Se precursor, the reaction required only $10 \mathrm{~min}$ at $90^{\circ} \mathrm{C}$ to synthesize $\mathrm{PbSe}$ nanocrystals. The size of the PbSe nanocrystal was controlled by varying the initial molar ratio of $\mathrm{Pb}: \mathrm{Se}$ at $1: 1,1: 2.5$ and 1:5 to yield PbSe nanocrystal sizes of 26.9, 21.4 and $13.7 \mathrm{~nm}$, respectively.

\section{MAGNETIC NANOPARTICLE SYNTHESIS}

Magnetic nanoparticles are considered one of the most promising inorganic nanoparticles because of their favorable applications in both biology and electronics. In this section, we describe an elaborate genetic engineering approach used for demonstrating magnetite biomineralization, subsequently describe a microfluidic strategy for the controlled biosynthesis of magnetite nanoparticles and finally explain Magnetococcus marinus-assisted drug delivery to a hypoxic region by exploring its native features. Finally, the role of biosynthesis in enhancement of the Co content and magnetic property of ferrites is presented.

For use in genetic engineering, Rhodospirillum rubrum lacks the intrinsic ability to synthesize magnetic nanoparticles; thus, a set of genes was introduced from the magnetotactic bacterium Magnetospirillum gryphiswaldense. ${ }^{6}$ In M. gryphiswaldense, Fe ions first enter the cytoplasm; this process is followed by magnetosome membrane 


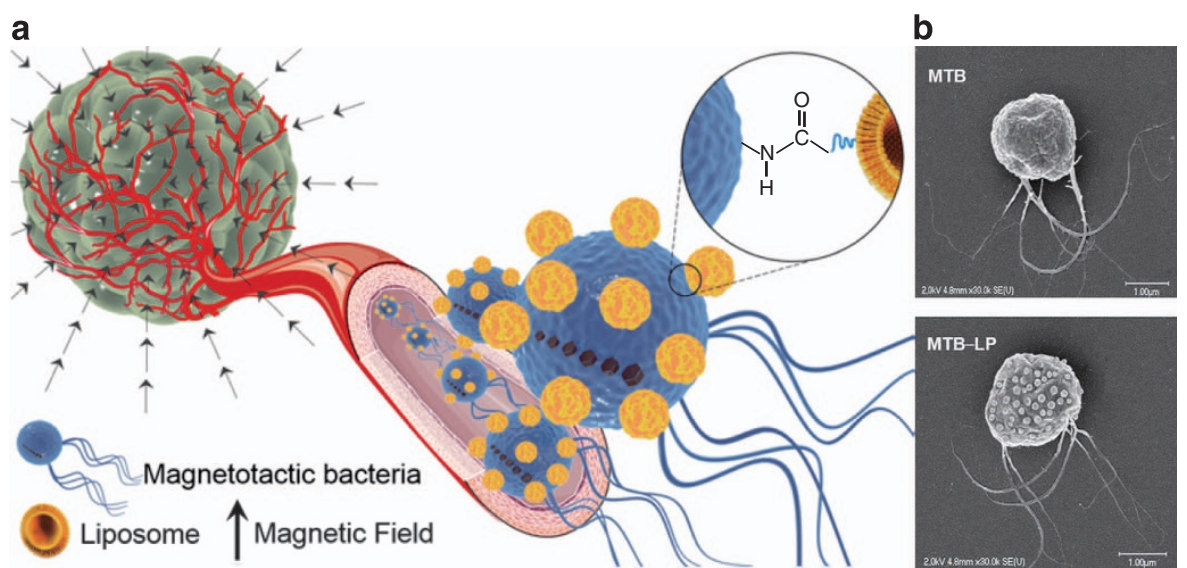

Figure 4 (a) Covalent binding of nanoliposomes to the surface of magnetotactic bacteria used as self-propelled therapeutic agents. (b) Scanning electron microscope image of the magnetotactic bacteria before and after conjugation with the liposomes. Reproduced with permission. ${ }^{29}$ Copyright 2014 , American Chemical Society.

synthesis and crystallization and subsequently by magnetosome arrangement and placement in the intracellular environment. All of these functions in M. gryphiswaldense are controlled by mam $A B$ genes and aided by three auxiliary genes, namely, mamGFDC, mms 6 and mamXY. The $R$. rubrum transformed with mam $A B$ or mam $A B$ in combination with mamGFDC did not exhibit magnetite synthesis. In contrast, $R$. rubrum transformed with $m m s 6$ and the mamAB-mamGFDC combination showed a significant increase in the $\mathrm{Fe}$ content in the cells, and unorganized nanoparticles were observed and identified as hematite. Addition of mamXY to the cells with mamAB, mms 6 and mamGFDC, which are denoted as R. rubrum A6GX (Species genus STRAIN), led to the synthesis of 24-nm magnetite nanoparticles capped with a thick layer of proteins. Because feoAB1 in $M$. gryphiswaldense controls the arrangement of magnetosomes, ${ }^{6}$ the introduction of feoAB1 to $R$. rubrumA6GX enabled the cells to synthesize magnetosomes with chains $440 \mathrm{~nm}$ in length. In those genetic engineering approaches, the proteins coated on the nanoparticles were identified using molecular techniques in which the proteins were removed using detergents and were reported as $12.4 \mathrm{kDa}$ in size.

Jung et al. ${ }^{4}$ adopted a microfluidic approach for biosynthesizing homogenous magnetic nanoparticles. A precursor metal ion mixture containing $\mathrm{FeSO}_{4} \cdot 7 \mathrm{H}_{2} \mathrm{O}$ and $\mathrm{MnCl}_{2} \cdot 4 \mathrm{H}_{2} \mathrm{O}$ was pumped in one channel, and recombinant E. coli expressing $P C$ and $M T$ was pumped into another channel. In addition to those two aqueous channels, the third oil-phase channel was pumped with fluorocarbon oil and polyethylene glycol. The three microchannels facilitated the formation of homogeneous droplets $250 \mu \mathrm{m}$ in diameter and $64.5 \mathrm{nl}$ in volume that encapsulated $3 \times 10^{5} \mathrm{E}$. coli cells. The resulting droplets were mixed thoroughly in a serpentine microchannel arrangement, after which the droplets were passed through an incubation channel for $5 \mathrm{~min}$ and were collected at the outlet, followed by $18 \mathrm{~h}$ of incubation at $37^{\circ} \mathrm{C}$. The microdroplets did not allow the encapsulated cells to experience the effects of the concentration gradient of the precursor metal ion mixture, and thus, $95 \%$ of homogenous magnetic nanoparticles with sizes of $5.2 \mathrm{~nm}$ were obtained. The as-prepared nanoparticles showed superparamagnetic behavior characterized with a vibrating sample magnetometer. A study used a microfluidic device with different engineered channels to prepare iron oxide nanoparticles as well as QDs and Au nanoparticles. ${ }^{28}$ The authors microencapsulated E. coli cell extracts using the permeable poly( $\mathrm{N}$-isopropylacrylamide) polymer, which allowed the metal ion precursors to bind with the encapsulated cell extracts. For aqueous droplet generation, five microfluidic channels were fabricated using a poly(dimethylsiloxane) soft lithography technique, and their endings were directed toward an orifice measuring $50 \mu \mathrm{m}$ in width and $110 \mu \mathrm{m}$ in height. The channels were fed with oil at the outer two channels and with poly(N-isopropylacrylamide) monomers with the cell extracts in the inner three channels. The poly( $\mathrm{N}$-isopropylacrylamide $)$ monomers were chemically polymerized, and the metal precursors subsequently bound to the proteins of the cell extracts for $\mathrm{Fe}_{3} \mathrm{O}_{4}, \mathrm{CdSe}$ and $\mathrm{Au}$ nanoparticle synthesis. The authors demonstrated size-controlled $\mathrm{Fe}_{3} \mathrm{O}_{4}$ and $\mathrm{CdSe}$ nanoparticles of approximately $5 \mathrm{~nm}$ in size with a standard deviation of $<1.6 \mathrm{~nm}$, and they also presented the concentration-dependent size control of Au nanoparticles.

For the applications of biosynthesized magnetic nanoparticles, Taherkhani et al. ${ }^{29}$ showed the ability of M. marinus to serve as a drug delivery carrier and to deliver therapeutic agents to hypoxic regions of tumors using the self-propulsion property of the bacteria (Figure 4). The bacteria-synthesized magnetic nanoparticles were aligned into magnetosomes. M. marinus shows an aerotatic behavior, that is, the ability to move in response to oxygen gradient toward a hypoxic region. (Using this property of the bacteria to move towards hypoxia region, the aerotatic bacteria were used to deliver drugs to the hypoxic regions of tumors). In general, delivery of drugs through diffusion to the hypoxic regions of tumors is difficult because such regions are devoid of blood vessels. The authors used drugloaded liposomes to covalently conjugate the liposomes to the magnetotactic bacteria through carbodiimide bonding. The number of liposomes loaded on the bacteria determined the navigation speed. With respect to cytotoxicity, no toxicity was observed for NIH/3T3 and J774 cells when treated at up to $10^{8}$ bacterial cells/well and for Colo205 cells when treated at up to $6 \times 10^{6}$ bacterial cells/well.

Because the magnetic property of $\mathrm{Fe}_{3} \mathrm{O}_{4}$ nanoparticles can be improved by adding Co, Geobacter sulfurreducens was incubated with $\mathrm{CoFe}(\mathrm{III})$-oxyhydroxide in a bicarbonate buffer under anaerobic conditions. ${ }^{30}$ The resultant extracellular matrixes were characterized using EDX, and the results indicated that a maximum of $23 \%$ of Co matched the stoichiometry of $\mathrm{CoFe}_{2} \mathrm{O}_{4}$. The TEM characterization showed a particle size of $8 \mathrm{~nm}$, and the reduction in particle size was proportional to the increase in the Co content. The $\mathrm{CoFe}_{2} \mathrm{O}_{4}$ nanoparticles showed a dramatic increase in their magnetic properties compared with that of iron oxide nanoparticles. In continuation of the previous study, the authors also conducted experiments involving $\mathrm{Zn}$ 
doping and investigated the role of $\mathrm{Zn}$ in saturation magnetization. ${ }^{31}$ G. sulfurreducens were exposed to a mixture of $\mathrm{ZnCl}_{2}$ and $\mathrm{FeCl}_{3}$ at different ratios for the different doping ratios. The authors found that an increase in the $\mathrm{Zn}$ content resulted in a size reduction of the zinc ferrites. The lattice spacing increased from 8.37 to $8.45 \AA$ as the $\mathrm{Zn}$ dopant concentration was increased. The saturation magnetization values at a temperature of $5 \mathrm{~K}$ increased from $72 \mathrm{emu} \mathrm{g}^{-1}$ for the undoped samples to $112 \mathrm{emu} \mathrm{g}^{-1}$ for $\mathrm{Zn}_{0.16}$ samples and remained unchanged until the dopant concentration reached 0.42 . Thereafter, the values decreased as the $\mathrm{Zn}$ dopant concentration increased and fell to $12 \mathrm{emug}^{-1}$ for $\mathrm{Zn}_{0.92}$ samples. The $\mathrm{X}$-ray magnetic dichroism measurements indicated that the increase in the $\mathrm{Zn}$ dopant concentration resulted in the replacement of $\mathrm{Fe}^{3+}$ by $\mathrm{Zn}^{2+}$, leading to a decrease in the octahedral site $\mathrm{Fe}^{2+}$ and tetrahedral site $\mathrm{Fe}^{3+}$ but an increase in the octahedral site $\mathrm{Fe}^{3+}$. For use as contrast agents in MR imaging, the $\mathrm{Zn}_{0.16}$ samples showed greater than fivefold superior contrast enhancement compared with the commercial MRI contrast agent Feridex.

\section{VIRUS-TEMPLATED NANOPARTICLES}

Viruses are considered to be independent natural nanoparticles and can facilitate tailoring of advanced nanoporous materials to specific requirements. To develop advanced nanoporous materials, M13 bacteriophages approximately $880 \mathrm{~nm}$ in length and $6.6 \mathrm{~nm}$ in diameter were assembled via layer-by-layer assembly to form a film. ${ }^{32}$ Covalent interaction was achieved through EDC crosslinking and used for the layer-by-layer assembly (Figure 5).

The bacteriophage film exhibited 59\% surface porosity and $40 \%$ surface roughness. After the layer-by-layer assembly, the substrates were dipped in a $\mathrm{TiCl}_{4}$ solution to deposit $\mathrm{Ti}$ ions, which were subsequently hydrolyzed to form $\mathrm{TiO}_{2}$ nanoparticles via the sol-gel method. The surface morphology of the as-prepared $\mathrm{TiO}_{2}$ film showed a mesh-like assembly with nanowires $10 \mathrm{~nm}$ in diameter. These meshes had pore sizes varying from 4 to $15 \mathrm{~nm}$ on the surface and inside, as shown in a cross-sectional view. The reaction temperature and time were demonstrated to be critical in interconnecting the wires to avoid overgrowth. Because $\mathrm{TiO}_{2}$ can be sensitized with $\mathrm{Au}$ for optoelectronic applications, the ability of the bacteriophage film to embed Au nanoparticles was examined through dip coating and drop coating; drop coating showed enhanced nanoparticle penetration into the network because of capillary forces. The $\mathrm{TiO}_{2}$ was coated after deposition of the Au nanoparticles. The distribution and concentration of the Au nanoparticles were allowed to adjust in the networks, thus enabling the localized surface plasmon resonance of the bacteriophage films to be controlled. The X-ray photoelectron spectroscopy measurements indicated that the concentration gradient in the placement of the nanoparticles from the substrates depended on the thickness of the virus coating (Figure 5).

In contrast to the aforementioned virus-based layer-by-layer assembly, M13 bacteriophages alone were used as templates for the synthesis of nano-barium titanate (BTO) nanostructures (Figure 6). ${ }^{33}$ Genetically engineered M13 bacteriophages with three glutamates on the $\mathrm{N}$-terminus of the major capsid $\mathrm{p} 8$ were incubated with barium glycolates, followed by titanium glycolates. Electrostatic integration had a major role in the interaction of the viruses with barium glycolates to form a barium-containing complex 1 (virus+barium glycolate). Subsequently, complex 1 was coated with titanium glycolates to form titanium- and barium-containing complex 2 (virus +barium glycolate+titanium glycolate) through interactions of electrostatic and hydrogen bonding. Complex 2 was subsequently calcined to form a perovskite crystal structure (BTO). Although the viruses were removed through calcination, their fibrous morphology (lengths of 50-100 nm) was retained. Subsequently, BTO was spin-coated on a polydimethylsiloxane layer and covered by indium tin oxide coated with polyethylene terephthalate. The indium tin oxide-coated polyethylene terephthalate was used as the top electrode, which formed a sandwich structure for piezoelectric evaluations. The resulting flexible nanogenerator with a size of $6.25 \mathrm{~cm}^{2}$ generated a short-circuit current and an open-circuit voltage of $300 \mathrm{nA}$ and $6 \mathrm{~V}$, respectively. The nanogenerator also demonstrated greater efficiency than the BTO nanoparticles assembled with the $\mathrm{C}$ nanotubes because of the dispersed structure of the BTO nanoparticles, which evolved from the viral templates. The viral template assembly was stable for up to 21000 cycles of repeated stress.

For biomedical applications, M13 viruses were engineered to display SPARC-targeting peptides (which are overexpressed in several cancer cells) of the $\mathrm{p} 3$ motif for specific targeting of prostate cancer cells, and proteins with the $\mathrm{p} 8$ motif were subsequently used to conjugate nanoparticles. $^{34}$ The triglutamate-peptide-modified M13 viruses allowed electrostatic assembly with positively charged nanoparticles (Figure 7) in which the polyethylene glycol-lipid formulated iron oxide nanoparticles were synthesized to assemble on the modified M13 viruses. The transverse relaxation values of the as-prepared M13-MNPs (magnetic nanoparticles) were measured. The SPARC-modified M13-MNP viruses retained the peptide-specific targeting of prostate cancers and were effective in in vivo MR

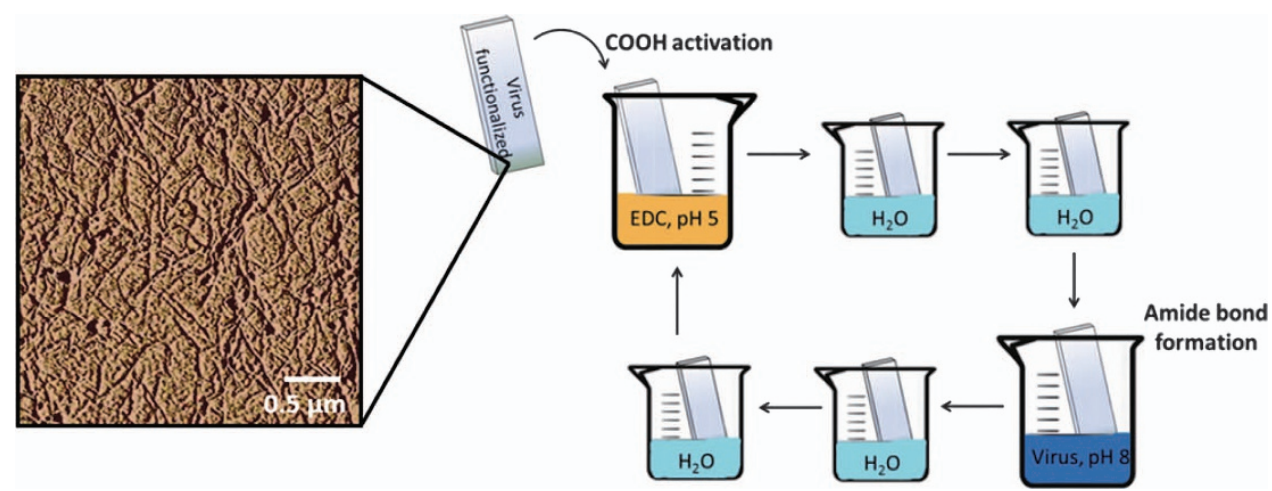

Figure 5 Atomic force microscopy image of the nanoporous materials formed using M13 bacteriophages as templates. Substrates such as glass, silicon wafer, plastics and metal foil coated with the viruses were activated with EDC to form amide bonds and dipped in a solution containing the viruses. The unbound cross-linkers and viruses were removed by dipping the substrate(s) in water. Reproduced with permission. ${ }^{32}$ Copyright 2014 , WILEY-VCH. 


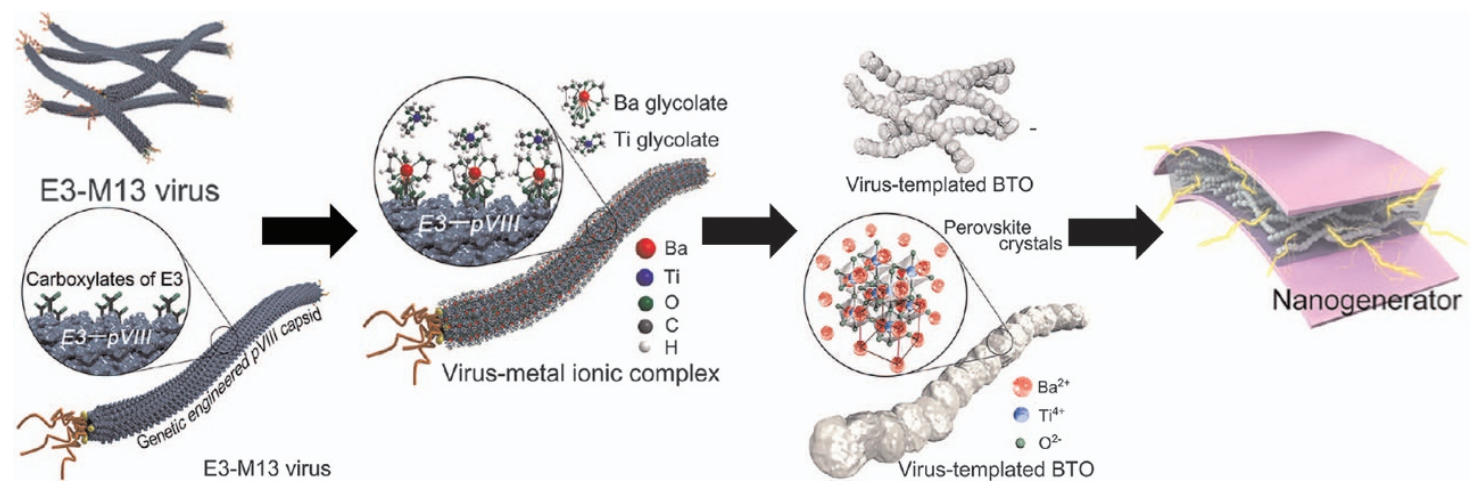

Figure 6 Schematic illustration of viral template-associated porous $\mathrm{BaTiO}_{3}$ nanostructure synthesis. Genetic engineering of $\mathrm{M} 13$ viruses with glutamates $\rightarrow$ incubation with barium glycolates and subsequently with titanium glycolates $\rightarrow$ complex 2 (virus+barium glycolate+titanium glycolate) calcined to form perovskite crystal structures $\rightarrow$ perovskite structure sandwiched with indium tin oxide glass for piezoelectric generation. Reproduced with permission. ${ }^{33}$ Copyright 2013, American Chemical Society.

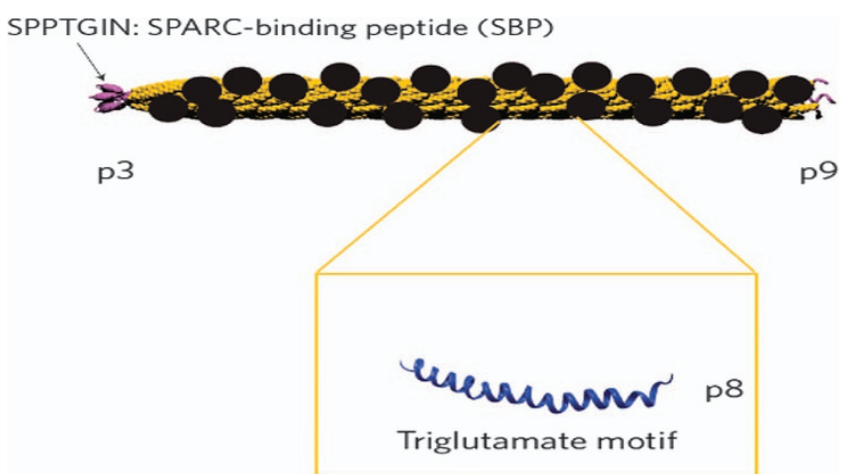

Figure 7 Schematic illustration of M13-bacteriophage-mediated targeting of magnetic nanoparticles for MRI. The M13 bacteriophages were modified with SPARC-binding peptides of the $\mathrm{p} 3$ motif and subsequently with $\mathrm{p} 8$ proteins with a triglutamate motif for multivalent assembly of iron oxide nanoparticles (black circles). Reproduced with permission. ${ }^{34}$ Copyright 2012, Nature Publishing Group.

imaging. Furthermore, compared with SPARC-functionalized MNPs, SPARC-modified M13-MNPs exhibited an 11-fold improvement in uptake in cancer cells.

\section{MICROBIAL ORGANIC NANOPARTICLES AND PROTEINS IN COORDINATION WITH DNA NANOPARTICLES}

Although proteins are naturally occurring nanostructures, isolating or assembling them into an integrated structure in an ex vivo environment remains challenging. Studies involving the isolation and assembly of protein nanostructures are discussed in this section. Bacterial cellulose (BC) nanofibers are gaining importance because of their high strength, elasticity and water-holding capacity. To impart a bactericidal property to the nanofibers, a combination of bactericidal chitin (Ch) with BC nanofibers was developed to form a nanocomposite of $\mathrm{BC}-\mathrm{Ch}$ and in a process that is considered a green approach. ${ }^{35}$ Chitin forms chitosan after deacetylation; thus, chitin was deacetylated through acid hydrolysis, tetramethylpiperidine-1-oxyl radical-mediated oxidation (TEMPO-mediated oxidation), or partial deacetylation methods involving $\mathrm{NaOH}$. The degree of deacetylation was estimated from the resonance peaks of NMR measurements. Using these deacetylation approaches, different degrees of deacetylation of 86 (acid hydrolysis), 87 (TEMPO-mediated oxidation) and
$79 \%(\mathrm{NaOH}$ deacetylation) were obtained. Among these approaches, $\mathrm{NaOH}$ deacetylation $\left(\mathrm{Ch}_{79 \mathrm{~d}}\right)$ showed the strongest bactericidal property. Acetobacter aceti has the capacity to produce $50-100-\mathrm{nm}$ wide nanofibrils. ${ }^{35}$ Therefore, A. aceti was fed with $\mathrm{Ch}_{79 \mathrm{~d}}$ to biosynthesize bio-BC- $\mathrm{Ch}_{79 \mathrm{~d}}$ nanocomposites. For comparison, a post-modification strategy that entailed collecting $\mathrm{BC}$ from A. aceti and combining it with $\mathrm{Ch}_{79 \mathrm{~d}}$ to form post-BC-Ch used. Comparison between bio-BC-Ch $79 \mathrm{~d}$ and post-BC-Ch indicated that the biosynthesized bio- $\mathrm{BC}-\mathrm{Ch}_{79 \mathrm{~d}}$ exhibited improved tensile and mechanical strengths because of the extensive hydrogen bond formation and hierarchical branching caused by fibril aggregation, ${ }^{36}$ whereas the continuity was absent in post-modification because of mechanical disintegration.

MacKay et al. ${ }^{37}$ reported that selected proteins can assemble into nanostructures when the temperature exceeds a specific point known as the transition temperature. The elastin-like polypeptide has a sequence in the form of (Val-Pro-Gly- $\left.\mathrm{X}_{\mathrm{aa}}-\mathrm{Gly}\right)_{\mathrm{n}}$ in which $\mathrm{X}_{\mathrm{aa}}$, can be substituted, and the suffix ' $n$ ' represents the number of repeat units. For example, a monoblock polypeptide was created with an isoleucine and valine substitution at $\mathrm{X}_{\mathrm{aa}}$ to form I24 and V96/V192, respectively. Similarly, to create a diblock polypeptide, hydrophilic serine and hydrophobic isoleucine blocks were used at $\mathrm{X}_{\mathrm{aa}}$ to form S48I48. The genetic sequence of the four elastin-like polypeptides, that is, I24, V96, V192 and S48I48, were introduced separately into four E. coli bacterial cultures using the pET25B(+) vector. All of these peptides assembled to different sizes when incubated at different concentrations at $28^{\circ} \mathrm{C}$. Among these peptides, the S48I48 amphiphilic diblock polypeptides formed the smallest assembly of $24 \mathrm{~nm}$, whereas the other peptides of I24, V96 and V192 formed assemblies of $0.4-1.3 \mu \mathrm{m}$. Figure 8 shows the ability of the monoblock peptides to assemble together and ability of the diblock peptides to segregate from the monoblock peptides when the transition temperature is attained. To evaluate those processes, the peptides were fluorescently labeled at the N-terminus with red rhodamine and green carboxyfluorescein probes. The fluorescence from a V96red (rhodamine)/V192green (carboxyfluorescein) mixture with a combination of both colors confirmed the presence of a co-localized assembly at conditions greater than the transition temperature. The overlay of both colors mixed together was quantitatively confirmed through standard mathematical correlation, namely, Pearson's coefficient. Similarly, V96red (rhodamine)/I24green (carboxyfluorescein) exhibited co-localization. Conversely, the probes in the V96red (rhodamine)/S48I48green (carboxyfluorescein) combination self-sorted from each other because of a change in 
a

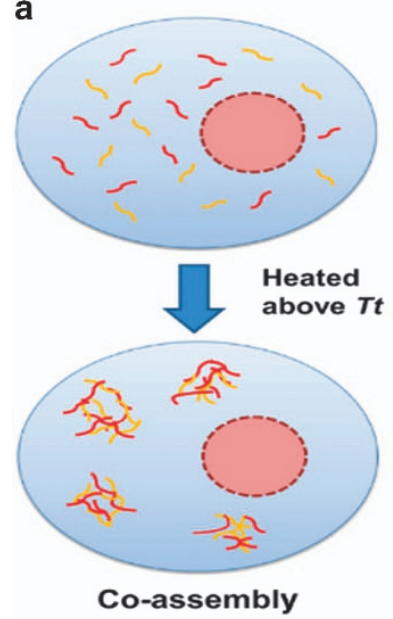

b

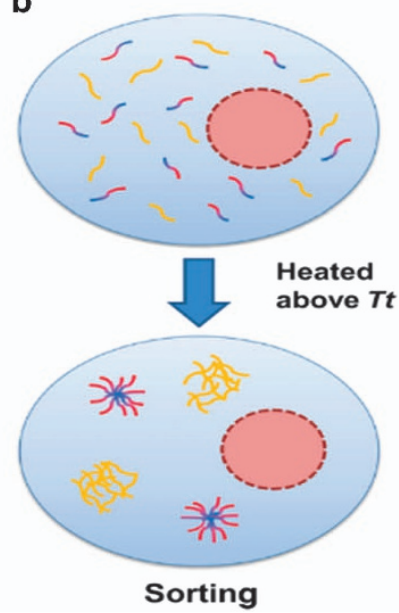

Figure 8 Schematic representation of (a) monoblock polymer exhibiting coassembly behavior and (b) diblock and monoblock polymers exhibiting sorting behavior above the transition temperature. Reproduced with permission. ${ }^{37}$ Copyright 2014, WILEY-VCH.

hydrophobicity. When the mixtures were used at conditions below the transition temperature, only a mixture of the dyes was observed, indicating that no assembly occurred. These genetically modified polypeptide structures could be introduced for temperature-controlled sorting or as co-assembling functional proteins.

Viral proteins are readily assembled into capsids to encapsulate nucleic acids and might assemble into different nanocompartment structures, such as donut-shaped structures derived from the assembly of the T4 viral proteins. ${ }^{38}$ The T4 bacteriophage that infects E. coli has a tail region composed of gp18 and gp15, which are major tube sheath and minor capping proteins, respectively. These gp18 and gp15 proteins individually form tube and hexameric ring assemblies, but the assembled structure is questionable when the proteins coexist (Figure 9). To clarify this process, gp 15 with a $6 \times$ histidine tag at the C-terminal end (gp15his) and gp18 with a streptavidin-binding tag at the C-terminal (gp18sbp) were synthesized, and purification was performed using Ni-NTA beads accompanied with biotin-assisted elution. These C-terminal modifications did not affect the original structures of the proteins when incubated individually. Instead, gp15his assembled with gp18sbp, resulting in the formation of donut-shaped structures with a thickness of approximately $20 \mathrm{~nm}$, which was similar to that of the tube assembly of gp18, because of the ability of the helical structure to interact directly.

Coating DNA with such binders as lipids, proteins and polymers is an effective method for modifying the flexibility, thickness and interaction characteristics of DNA and is crucial for successful gene delivery. In this context, protein nanoparticles of the desired sequence were synthesized by introducing the constructed genes. ${ }^{39}$ The polymers incorporated with DNA aggregates were designed to reveal stable single DNA integration with the proteins in the diblock form in which one bulk block contains 400 amino acids (C4) for stabilization and the second short cationic block contains 12 amino acids for holding the DNA. The short cationic blocks are composed of two types of blocks, one with 12 lysines (L12) and another with 6 histidines and 6 lysines (HL6). The nucleic acid sequence that codes for the desired C4L12 and C4HL6 were introduced via electroporation into the Pichia pastoris GS115 strain for biosynthesis. The proteins were collected from the cell-free supernatants and characterized

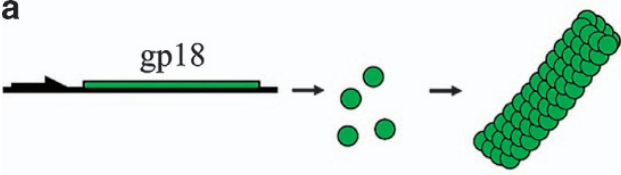

b

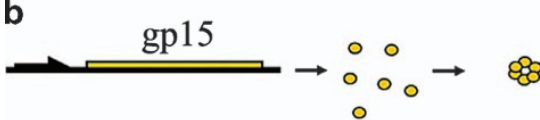

c

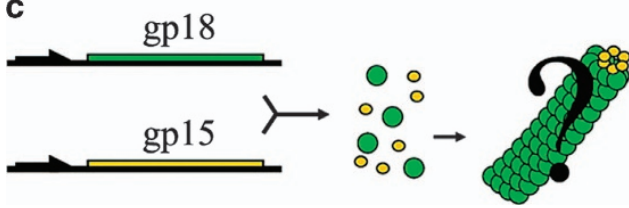

Figure 9 Schematic illustration of the synthesis and assembly of T4 viral tail tube subunits. Synthesis and assembly of gp18 tubes (a) and gp15 hexameric rings (b), and co-synthesis of gp18 and gp15 assembled into unknown structures (c). Reproduced with permission. ${ }^{38}$ Copyright 2007, American Chemical Society.

using sodium dodecyl sulfate-polyacrylamide gel electrophoresis and matrix-assisted laser desorption/ionization time-of-flight analysis. The length of C4L12/C4HL6 was approximately $620-650 \mathrm{~nm}$, and the width was $1 \mathrm{~nm}$. A $0.25 \mathrm{M}$ salt concentration disintegrated the diblock constructs from the loaded DNA.

\section{CONCLUDING REMARKS AND PROSPECTS}

Nanoparticle biosynthesis is gradually attracting considerable interest because of its simplicity, cost effectiveness and eco-friendliness. In this review, we summarize the recent advances in the unicellular- or subcellular-associated synthesis of nanoparticles, including metals, metal oxides and viral protein-related particles, and nanoconstructs derived using bacterial DNA, proteins or viral proteins as templates. It is known that the biosynthesis of metal nanoparticles can readily occur from the microorganisms that exhibit the heavy metal-resistant property and are found in industrial pollutant sewage. The common feature of these microorganisms is that they protect themselves via the process of reducing metal ions to non-valent metal particles. Mechanisms for reducing metal ions usually involve donating electrons from the metabolic products, for example, the thiol protein, thiol amino acid, cytochrome, DNA, RNA, NADPH and other various reductases. For example, the reduction process that forms gold nanoparticles in the biosystems receives electrons from proteins $8,14,15$ or NADPH coupled with glutathione. ${ }^{17,18}$ The Ag nanoparticle preparations were observed in biosynthesis via electron donation from the enzyme-mediated reducing process, ${ }^{9}$ plasmid scaffolded and reduced process, ${ }^{11}$ and cytochrome-supporting reduction. ${ }^{12}$ The $\mathrm{Cu}$ and FeMn nanoparticle synthesis processes used proteins and reducing-enzyme-mediated reducing processes, respectively. ${ }^{4,10}$ Although $\mathrm{Au}, \mathrm{Ag}, \mathrm{Cu}$ and iron oxide nanoparticles are the most frequently studied compositions, certain problems remain to be solved for biosynthesis of these nanomaterials in terms of inhomogeneity and polydispersity. The unclear mechanisms of the biosynthesis of $\mathrm{Ag}, \mathrm{Cu}$ and magnetic $\mathrm{Fe}_{3} \mathrm{O}_{4}$ nanoparticles are another issue to be resolved. ${ }^{6,9,13}$ For example, the investigation of the mechanisms that cause the silver-resistant Morganella spp. to form Ag, Cu nanoparticles and magnetosomes derived from $M$. gryphiswaldense is in a preliminary stage. It was found that the identified gene clusters were 
involved in reducing the metallic ions and maintaining the stability of the nanoparticles, but the details of how the function of the specific gene contributes to the nanoparticles formation are still unknown. Silver oxide can be obtained in the form of $\mathrm{Ag}_{2} \mathrm{O}$ in bacteria, but the detailed mechanism is also unclear. $^{20}$

Nevertheless, these current advanced strategies show significant improvement in the quality of the nanoparticles synthesized compared with those synthesized using the initial primitive method. ${ }^{28,33}$ In the earlier methods, one main reason for the inhomogeneity of the nanoparticles in terms of size and shape was incubation of the bacteria with precursor solutions, which caused the composite action of more than one protein to spoil the quality. In contrast, all strategies discussed in this review (including the use of biotemplates, segregation of proteins and miniaturization of incubation chambers with microfluidics) contribute to improving the homogeneity of nanoparticles. Further improvement in bacteria-based biosynthesis might enable an improved yield of nanoparticles, thus attracting considerable attention in various applications.

For biomedical applications, semiconductive QDs are the most promising potential materials for biomedical diagnosis. However, the biocompatibility issue is a major concern for any further applications. Xiong et al. ${ }^{26}$ designed targetable cellular beacons for diagnosis of pathogens using the biosynthesis strategy coupled with the antibody-combination ability of $S$. aureus. Taherkhani et al. ${ }^{29}$ presented another facile strategy in an application for cancer therapy using the magnetosomes derived from the bacteria $M$. marinus MC-1. Ghosh et al. ${ }^{34}$ used the engineered M13 virus and combined the phage display technique and magnetic nanoparticles in targeting diagnosis for prostate cancer. Furthermore, quasi-biosynthesized $\mathrm{Ag}_{2} \mathrm{Se}$ QDs are good candidates for use as low-toxicity fluorescent tags for in vivo imaging diagnosis. ${ }^{25}$ Overall, these cases provide selected examples of biomedical applications of biosynthesized nanomaterials. However, more comprehensive studies using biosynthesized nanoparticles as nanomedicine still remain to be explored.

Robotics is a field that combines mechanical, electrical and computer engineering. The micro-robotic miniaturization of actuators, propulsion, steering, energy storage and energy convertors poses a great challenge. In nature, substitutes for these components are already available in the form of proteins and motile bacteria, such as magnetotactic bacteria. These bacteria are used to drive polystyrene beads via the attachment of eight bacteria. ${ }^{40}$ In this context, engineering research has gradually progressed with biological assistance in the following sequence: magnetotactic bacterial movement with external hardware control $\rightarrow$ magnetotactic bacterial movement without external control $\rightarrow$ megnetotactic bacterial movement with directional control. However, scientists are also interested in using the flagella protein with a size of 300 hydrogen atoms for propulsion. ${ }^{41}$ In this case, the separation, purification and integration of natural proteins present the largest challenge. Once the bio-propeller is ready, it can be easily integrated on biosynthesized metal nanoparticles with a capping protein. Otherwise, the propeller protein by itself might act as the reducing and capping agent for ready-to-use nanorobots. To date, most successful programmable molecular robots are designed with DNA. ${ }^{42}$ However, a major limitation exists for in vivo experiments because the movement depends on the chemical stimuli. Thus, magnetic stimuli are preferred because they cause the least disturbance to the in vivo conditions. An Au nanocluster protected by lysozymes, which are widely present in biological fluids, showed efficient biocidal activity even against antibiotic-resistant cells. This effect was apparent because of the complementary functional effects of the Au nanocluster and lysozymes coated on the nanocluster. ${ }^{43}$ Lysozyme-stabilized Au nanoclusters not only exhibit antimicrobial properties but also recognize a broad range of pathogens. For applications of nanoformulated robotics, a combination of bioassociated nanomaterial preparations and the properties of biotemplates, for example, protein natures and the specific shape of a microorganism, would be versatile in integrated electronics and biomedicine. In a previous study, magnetosomes acted as nanorobots for cell sorting and were used to sort granulocytes and monocytes from lymphocytes. ${ }^{44}$ Applications in MR imaging and the combination of magnetic guiding and self-propelling properties of bacteria indicate that magnetosomes could also act as powerful therapeutic agents in biomedical applications. In short, biosynthesized nanoparticles are also promising as functional nanomaterials for robotics.

\section{CONFLICT OF INTEREST}

The authors declare no conflict of interest.

\section{ACKNOWLEDGEMENTS}

This work was supported by the National Science Council (NSC103-2113-M006-008-MY2) of Taiwan and in part by the Headquarters of University Advancement at the National Cheng Kung University, which is sponsored by the Ministry of Education, Taiwan, ROC.

1 Pronk, J. T., Liem, K. P., Bos, J. \& Kuenen, G. Energy transduction by anaerobic ferric iron respiration in Thiobacillus ferrooxidans. Appl. Environ. Microbiol. 57 2063-2068 (1991)

2 Klaus, T., Joerger, R., Olsson, E. \& Granqvist, C.-G. Silver-based crystalline nanopar ticles, microbially fabricated. Proc. Natl Acad. Sci. USA 96, 13611-13614 (1999).

3 Bansal, V., Rautaray, D., Bharde, A., Ahire, K., Sanyal, A., Ahmad, A. \& Sastry, M. Fungus-mediated biosynthesis of silica and titania particles. J. Mater. Chem. 15, 2583-2589 (2005)

4 Jung, J. H., Park, T. J., Lee, S. Y. \& Seo, T. S. Homogeneous biogenic paramagnetic nanoparticle synthesis based on a microfluidic droplet generator. Angew. Chem. Int. Ed. 51, 5634-5637 (2012).

5 Li, Y., Cui, R., Zhang, P., Chen, B.-B., Tian, Z.-Q., Li, L., Hu., B., Pang, D.-W. \& Xie, Z.-X. Mechanism-oriented controllability of intracellular quantum dots formation: the role of glutathione metabolic pathway. ACS Nano. 7, 2240-2248 (2013).

6 Kolinko, I., Lohße, A., Borg, S., Raschdorf, O., Jogler, C., Tu, Q., Pósfai, M., Tompa., E., Plitzko, J. M., Brachmann, A., Wanner, G., Müller, R., Zhang, Y. \& Schüler, D. Biosynthesis of magnetic nanostructures in a foreign organism by transfer of bacterial magnetosome gene clusters. Nat. Nanotechnol 9, 193-197 (2014).

7 Park, T. J., Lee, S. Y., Heo, N. S. \& Seo, T. S. In vivo synthesis of diverse metal nanoparticles by recombinant Escherichia coli. Angew. Chem. Int. Ed. 17, 7019-7024 (2012).

8 Murawala, P., Phadnis, S. M., Bhonde, R. R. \& Prasad, B. L. V. In situ synthesis of water dispersible bovine serum albumin capped gold and silver nanoparticles and their cytocompatibility studies. Colloids Surf. B Biointerfaces 73, 224-228 (2009).

9 Ramanathan, R., Field, M. R., O'Mullane, A. P., Smooker, P. M., Bhargava, S. K. \& Bansal, V. Aqueous phase synthesis of copper nanoparticles: a link between heavy metal resistance and nanoparticle synthesis ability in bacterial systems. Nanoscale $\mathbf{5}$ 2300-2306 (2013)

10 Salvadori, M. R., Ando, R. A., Oller do Nascimento, C. A. \& Corrêa, B. Intracellular Biosynthesis and removal of copper nanoparticles by dead biomass of yeast isolated from the wastewater of a mine in the Brazilian Amazonia. PLOS ONE 9, e87968 (2014).

11 Liu, J., Zhang, X., Yu, M., Li, S. \& Zhang, J. Photoinduced silver nanoparticles/ nanorings on plasmid DNA scaffolds. Small 8, 310-316 (2012).

12 Wörner, M., Lioubashevski, O., Basel, M. T., Niebler, S., Gogritchiani, E., Egner, N. Heinz, C., Hoferer, J., Cipolloni, M., Janik, K., Katz, E., Braun, A. M., Willner, I. Niederweis, M. \& Bossmann, S. H. Characterization of nanostructured surfaces generated by reconstitution of the porin MspA from Mycobacterium smegmatis. Small 3, 1084-1097 (2007).

13 Lin, I. W.-S., Lok, C.-N. \& Che, C.-M. Biosynthesis of silver nanoparticles from silver(I) reduction by the periplasmic nitrate reductase c-type cytochrome subunit $\mathrm{NapC}$ in silver-resistant E. coli. Chem. Sci 5, 3144-3150 (2014).

14 Correa-Llantén, D. N., Muñoz-Ibacache, S. A., Castro, M. E., Muñoz, P. A. \& Blamey, J. M. Gold nanoparticles synthesized by Geobacillus sp. strain ID17 thermophilic bacterium isolated from Deception Island, Antarctica. Microb. Cell Fact. 12, 75 (2013).

15 Johnston, C. W. Wyatt, M. A., Li, X., Ibrahim, A., Shuster, J., Southam, G. \& Magarvey, N. A. Gold biomineralization by a metallophore from a gold-associated microbe. Nat. Chem. Biol. 9, 241-243 (2013) 
16 Fayaza, A. M., Girilal, M., Rahmanb, M., Venkatesanc, R. \& Kalaichelvana, P. T. Biosynthesis of silver and gold nanoparticles using thermophilic bacterium Geobacillus stearothermophilus. Process Biochem. 46, 1958-1962 (2011).

17 Khan, S. A. \& Ahmad, A. Enzyme mediated synthesis of water-dispersible, naturally protein capped, monodispersed gold nanoparticles; their characterization and mechanistic aspects. RSC Adv 4, 7729-7734 (2014).

18 Zhang, M.-X., Cui, R., Tian, Z.-Q., Zhang, Z.-L. \& Pang, D.-W. Kinetics-controlled formation of gold clusters using a quasi-biological system. Adv. Funct. Mater. 20, 3673-3677 (2010).

$19 \mathrm{Ma}$, X., Chen, H., Yang, L., Wang, K., Guo, Y. \& Yuan, L. Construction and potential applications of a functionalized cell with an intracellular mineral scaffold. Angew. Chem. Int. Ed. 50, 7414-7417 (2011).

20 Dhoondia, Z. H. \& Chakraborty, H. Lactobacillus mediated synthesis of silver oxide nanoparticles. Nanomater. Nanotechnol 2, 2012 (2012).

21 Dameron, C. T., Reese, R. N., Mehra, R. K., Kortan, A. R., Carroll, P. J., Stteierwald, M.L., Burs, L.E. \& Winge, D.R. Biosynthesis of cadmium sulphide quantum semiconductor crystallites. Nature 338, 596-597 (1989).

22 Cui, R., Liu, H. H., Xie, H. Y., Zhang, Z. L., Yang, Y. R., Pang, D. W., Xie, Z. X., Chen, B. B., Hu, B. \& Shen, P. Living yeast cells as a controllable biosynthesizer for fluorescent quantum dots. Adv. Funct. Mater. 19, 2359-2364 (2009).

23 Luo, Q.-Y., Lin, Y., Li, Y., Xiong, L.-H., Cui, R., Xie, Z.-X. \& Pang, D.-W. Nanomechanical analysis of yeast cells in CdSe quantum dot biosynthesis. Small 4, 699-704 (2014).

24 Monrás, J. P., Díaz, V., Bravo, D., Montes, R. A., Chasteen, T. G., Osorio-Román, I.O., Vásquez, C. C. \& Pérez-Donoso, J. M. Enhanced glutathione content allows the in vivo synthesis of fluorescent CdTe nanoparticles by Escherichia coli. PLOS ONE 7, e48657 (2012).

25 Gu, Y.-P., Cui, R., Zhang, Z.-L., Xie, Z.-X. \& Pang, D.-W. Ultrasmall near-infrared $\mathrm{Ag}_{2} \mathrm{Se}$ quantum dots with tunable fluorescence for in vivo imaging. J. Am. Chem. Soc. 134, 79-82 (2012).

26 Xiong, L.-H., Cui, R., Zhang, Z.-L., Yu, X., Xie, Z., Shi, Y.-B. \& Pang, D.-W. Uniform fluorescent nanobioprobes for pathogen detection. ACS Nano. 8, 5116-5124 (2014).

27 Cui, R., Gu, Y.-P., Zhang., Z.-L., Xie, Z.-X., Tiana, Z.-Q. \& Pang, D.-W. Controllable synthesis of $\mathrm{PbSe}$ nanocubes in aqueous phase using a quasi-biosystem. J. Mater. Chem. 22, 3713-3716 (2012).

28 Lee, K. G., Hong, J., Wang, K. W., Heo, N. S., Kim, D. H., Lee, S. Y., Lee, S. J. \& Park, T.J. In vitro biosynthesis of metal nanoparticles in microdroplets. ACS Nano. 6 , 6998-7008 (2012).

29 Taherkhani, S., Mohammadi, M., Daoud, J., Martel, S. \& Tabrizian, M. Covalent binding of nanoliposomes to the surface of magnetotactic bacteria for the synthesis of self-propelled therapeutic agents. ACS Nano. 8, 5049-5060 (2014).

30 Coker, V. S., Telling, N. D., van der Laan, G., Pattrick, R. A. D., Pearce., C. I., Arenholz, E., Tuna, F., Winpenny, R. E. P. \& Lloyd, J. R. Harnessing the extracellular bacterial production of nanoscale cobalt ferrite with exploitable magnetic properties. ACS Nano. 3, 1922-1928 (2009).

31 Byrne, J. M., Coker, V. S., Cespedes, E., Wincott, P. L., Vaughan, D. J., Pattrick., R. A D., van der Laan, G., Arenholz, E., Tuna, F., Bencsik, M., Lloyd, J. R. \& Telling, N. D. Biosynthesis of zinc substituted magnetite nanoparticles with enhanced magnetic properties. Adv. Funct. Mater. 24, 2518-2529 (2013).
32 Courchesne, N.-M. D., Klug, M. T., Chen, P.-Y., Kooi, S. E., Yun, D. S., Hong, N., Fang, N.X., Belcher, A.M. \& Hammond, P.T. Assembly of a bacteriophage-based template for the organization of materials into nanoporous networks. Adv. Mater. 26 , 3398-3404 (2014).

33 Jeong, C. K., Kim, I., Park, K.-I., Oh, M. H., Paik, H., Hwang, G.-T., No, K., Nam, Y. S. \& Lee, K. J. Virus-directed design of a flexible $\mathrm{BaTiO}_{3}$ nanogenerator. ACS Nano. 7, 11016-11025 (2013).

34 Ghosh, D., Lee, Y., Thomas, S., Kohli, A. G., Yun, D. S., Belcher, A. M. \& Kelly, K. A. M13-templated magnetic nanoparticles for targeted in vivo imaging of prostate cancer. Nat. Nanotechnol 7, 677-682 (2012).

35 Butchosa, N., Brown, C., Larsson, P. T., Berglund, L. A., Bulone, V. \& Zhou, Q. Nanocomposites of bacterial cellulose nanofibers and chitin nanocrystals: fabrication, characterization and bactericidal activity. Green Chem. 15, 3404-3413 (2013).

36 Yamanaka, S. \& Sugiyama, J. Structural modification of bacterial cellulose. Cellulose 7 , 213-225 (2000).

37 Shi, P., Lin, Y.-A., Pastuszka, M., Cui, H. \& MacKay, J. A. Triggered sorting and coassembly of genetically engineered protein microdomains in the cytoplasm. Adv. Mater. 26, 449-454 (2014)

38 Daube, S. S., Arad, T. \& Bar-Ziv, R. Cell-free co-synthesis of protein nanoassemblies: tubes, rings, and doughnuts. Nano Lett. 7, 638-641 (2007).

39 Hernandez-Garcia, A., Werten, M. W. T., Stuart, M. C., de Wolf, F. A. \& de Vries, R. Coating of single DNA molecules by genetically engineered protein diblock copolymers. Small 8, 3491-3501 (2012).

40 Behkam, B. \& Sitti, M. Bacterial flagella-based propulsion and on/off motion control of microscale objects. Appl. Phys. Lett. 90: 023902 (2007).

41 Martel, S., Mohammadi, M., Felfoul, O., Lu, Z. \& Pouponneau, P. Flagellated magnetotactic bacteria as controlled MRI-trackable propulsion and steering systems for medical nanorobots operating in the human microvasculature. Int. J. Rob. Res $\mathbf{2 8}$ 571-582 (2009).

42 Muscat, R. A., Bath, J. \& Turberfield, A. J. A programmable molecular robot. Nano Lett. 11, 982-987 (2011).

43 Chen, W.-Y., Lin, J.-Y., Chen, W.-J., Luo, L., Diau, E. W.-G. \& Chen, Y.-C. Functional gold nanoclusters as antimicrobial agents for antibiotic-resistant bacteria. Nanomedicine 5, 755-764 (2010).

44 Matsunaga, T., Hashimoto, K., Nakamura, N., Nakamura, K. \& Hashimoto, S. Phagocytosis of bacterial magnetite by leucocytes. Appl. Microbiol. Biotechnol. 31, 401-405 (1989)

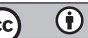

This work is licensed under a Creative Commons Attribution 4.0 International License. The images or other third party material in this article are included in the article's Creative Commons license, unless indicated otherwise in the credit line; if the material is not included under the Creative Commons license, users will need to obtain permission from the license holder to reproduce the material. To view a copy of this license, visit http:// creativecommons.org/licenses/by/4.0/
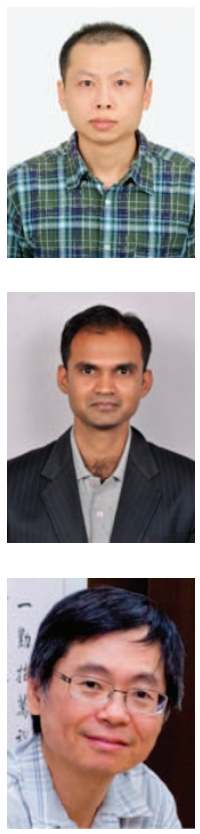

Cheng-Hung Luo received the M.S. (2004) and Ph.D. (2012) degrees in Microbiology from Institute of Medical Science, Tzu Chi University, Taiwan. He is currently joining Prof. C.-S. Yeh's lab and studying the bioapplication of nanoparticles as a postdoctoral fellow in National Cheng Kung University, Taiwan. His research covers the synthesis of nanoparticles and fabrication of NIR-triggered nanomaterials. For bio-applications, his interest in nanomaterials-mediated cancer therapy including the bio-targeting and bio-carrying applications.

Vijayakumar P. Shanmugam obtained his Ph.D. in Environmental Science from Tamil Nadu Agricultural University, India. Following this, from 2007, he pursued his postdoctoral studies on the bioapplication of nanoparticles, in the group of Dr B.L.V. Prasad, National Chemical Lab, India, Prof. J.M. Zen, National Chung Hsing University, Taiwan and Prof. C.S.Yeh, National Cheng Kung University, Taiwan. Currently, he is a Scientist C in Institute of Nano Science and Technology, Mohali, India. His research interest covers the synthesis and bioapplications of nanoparticles.

Chen-Sheng Yeh received a M.S. degree from National Tsing Hua University, Taiwan, and a Ph.D. degree in Chemistry from University of Georgia, USA, in 1993. He then worked as postdoctoral fellow at Department of Chemistry in Purdue University, USA. He started as an Associate Professor at the Department of Chemistry, National Cheng Kung University, Taiwan, in 1995. He was promoted to Professor and Distinguished Professor in 2001 and 2009, respectively. His research focuses on the development of functional nanomaterials in biological applications and the area of nanostructured characteristics. 